The effectiveness of multimodal texts in enhancing student's level of academic performance in Afro - Asian literature in English of Grade VIII students in Pedro Guevara Memorial National High School, Santa Cruz District, Division of Laguna

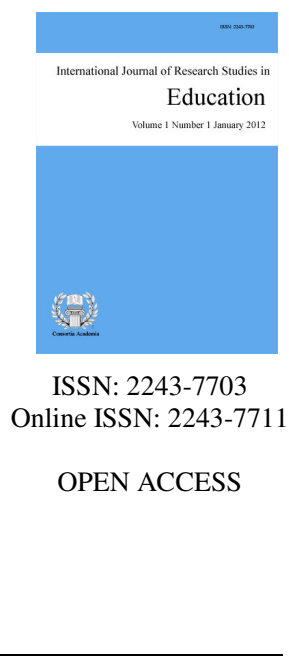

Tope, Jenifer $\bowtie$

Emilio Aguinaldo College,Philippines (jenifertope.mnl@eac.edu.ph; jenifer.tope@deped.gov.ph)

$\begin{array}{lll}\text { Received: } 30 \text { March } 2021 & \text { Revised: } 17 \text { May } 2021 & \text { Accepted: } 30 \text { May } 2021\end{array}$

\title{
Abstract
}

This paper puts forth the need for Multimodal Texts in Enhancing the Level of Performance in Afro - Asian Literature in English of Grade Eight Students. The samples of the study consisted of 40 secondary English teachers and 360 public secondary school students. The constructed Questionnaire which was based on the Multimodal Literacy Scale was used to assess the level of effectiveness of multimodal texts in terms of their characteristics and components. To determine the level of academic performance in Afro - Asian Literature in English of Grade 8 students of Pedro Guevara Memorial National High School, validated pre-assessment and post-assessment were used. The questionnaires and pre and post assessments were validated by English master teachers. To determine the effectiveness of the multimodal texts in terms of its characteristics and components, questionnaires were used. The data collected from their responses on the questionnaires were analyzed in terms of weighted mean. Results show that the multimodal text is extremely effective as to its characteristics in terms of usability, suitability, and consistency. It is evidently usable, suitable, consistent, and well laid out as validated by the master teachers and teachers in Pedro Guevara Memorial National High School. The level of academic performance of the experimental group is much higher than the level of performance of the control group as presented in the results of pretest and posttest took by the learners. There is a significant difference between the pre-assessments and post-assessments of the control group and experimental group. Thus, the null hypothesis was rejected which states that developed multimodal texts had a positive effect on the students learning of Afro - Asian Literature. They can result in greater depth of understanding by presenting multiple input modalities and increasing motivation among learners.

Keywords: multimodal, blended learning, performance, assessment, distance learning, supplementary materials, Afro-Asian literature 


\section{The effectiveness of multimodal texts in enhancing student's level of academic performance in Afro - Asian literature in English of Grade VIII students in Pedro Guevara Memorial National High School, Santa Cruz District, Division of Laguna}

\section{Introduction}

Our country is fighting the challenge brought about by the coronavirus disease 2019 (COVID-19) pandemic, Department of Education (DepEd) adopted and implemented the flexible model of blended learning. As the classes resumed, unceasing students' concerns and teachers' outcry were in the limelight - exposing the disadvantages that these learning solutions are posing. Learning in the New Normal is a challenge for the teachers, students, and even parents. The teaching and learning process would be very hard because there are no face-to-face classes that we are used to. The learning environment amidst the COVID-19 pandemic will be very different. There are different Learning Modalities that schools may employ. The number of COVID-19 Cases are reported in the Municipality of Sta. Cruz, Division of Laguna. The province of Laguna started the school year 2020-2021 with blended learning where there will be Online and Modular Classes at all levels.

Multimodal Text has a direct linkage in, DepEd Order No. 011, Series of 2020, the Department of Education (DepEd) adopts the Revised Guidelines on the Alternative Work Arrangement in the Department of education during the Period of State of National Emergency due to COVID-19 Pandemic. Multimodal texts combine two or more modes such as written language, spoken language, visual (still and moving image), audio, gestural, and spatial meaning. Examples of multimodal texts are slide decks (PowerPoint presentations), storyboards, printed worksheets, and digital stories. The use of this Motivational Multimodal text is to ensure that students are acquiring knowledge and skill that are deemed essential for their success in basic education learning in literature to meet the quality standards vital for their emersion in the millennial spectrum where highways on the air had been solidly established through internet advancement in spawning progress in their respective communities as a solid foundation for building a strong nation as their competitive edge with their counterpart in the global village.

On May 15, 2013, the Enhanced Basic Education Act of 2013, more commonly known as the K-12 Program, was signed into law in the Republic of the Philippines (Official Gazette of the Republic of the Philippines, 2013). According to the Department of Education of the Philippines (DepEd) Grade 8 curriculum guide, the English curriculum for students in the eighth grade level of the K-12 Program will primarily focus on African-Asian or Afro-Asian literature (Republic of the Philippines Department of Education, 2012). By the end of the First quarter, students in the eighth grade are expected to demonstrate an "understanding of the different genres through the types contributed by Afro-Asian countries to express appreciation for Afro-Asian heritage" (Republic of the Philippines Department of Education, 2012, p. 34). This ensures that the learners are exposed to Asian and African cultures through literature.

Most Essential Learning Competencies or MELC, according to DepEd, "are defined as what the students need, considered indispensable, in the teaching-learning process to building skills to equip learners for subsequent grade levels and subsequently, for lifelong learning". The MELC's will enable the teachers to focus their instruction on the most essential and indispensable competencies that our learners must acquire in this new normal education.

When I did my self-reflection at the end of the first quarter, I realized that I would have to use multimodal texts as a tool that is based on Most Essential Learning Competencies (MELC) for my online class. This tool would enhance the level of performance of my learners while we are in the new normal because it is a combination of digital and printed materials. I know that my learners are considered 21st-century learners and most of them are visual learners. They will not find it boring because there will be moving images instead of still 
pictures or merely printed material. It will help students not only improve comprehension but also increase motivation. These will be based on MELC 14 of English 8. The learners will be able to analyze literature as a mirror to a shared heritage of people with diverse backgrounds. This Multimodal Texts will include digital stories and printed activity sheets. At the end of the week, an online assessment using google forms will be given to the learners to check their learning and progress. Learning in the new normal is a challenge for the teachers, students, and even parents. The Department of Education confirmed that this school year will undergo blended learning approaches.

Blended learning is a combination of both online and offline learning methodologies with the use of technology. Online is when the students study with their teacher and classmates through an application that uses a webcam while offline is when the teacher provides the students with the lesson, seatwork, or assignment that they can finish at their own pace, within the deadline. All works are submitted and graded online. This new way of learning brought by the COVID-19 pandemic can be an additional challenge during this tough time. And since going back to the "normal" we're all accustomed to isn't going to happen anytime soon, let's all do the best we could to adjust and make this current situation work. Remember, the goal of online learning is to keep the students engaged academically to retain what they have learned.

In the 21 st century, young people live and learn in a technological world that is fast-paced and in a constant state of change. As technology becomes more and more accessible outside of the classroom, educators are challenged to re-consider the literacy skills required to be successfully literate. Enacting literacy teaching and learning in and for the 21st century requires teachers to update their pedagogical knowledge, skills and contextual understanding of the world children live and learn in. According to Capulso (2020) in his study of Braving the K-12 Education in the Philippines Amidst The COVID-19 Pandemic, the K-12 curriculum focuses on the learner's acquisition of the 21st-century skills (New Learning Goals). One of them is learning and innovation skills. This includes adaptability, creativity, critical thinking curiosity, higher-order thinking skills, managing complexity, problem-solving, risk-taking, self-direction, and sound reasoning. The $\mathrm{K}$ to 12 curriculum covers many areas to develop 21st-century learning skills. The adaption of Bloom's taxonomy to cater to the needs of the changing times gave the Learning Resource Materials an advantage to using technology through multimedia.

Recent developments in the Philippines have prompted the Philippine government to push for a new basic education curriculum as mentioned by Barrot (2018). Along with these changes is the adoption of the new English curriculum known as the Language Arts and Multiliteracies Curriculum (LAMC). It examined the K-12 English Curriculum in the Philippines from a 21st-century learning perspective. This education reform should not only focus on preparing students for competitive employment and entrepreneurship, narrowing development gaps, addressing the crowded curriculum, and integrating ICT. Equally important is transforming them into socially critical and productive citizens and equipping them with skills necessary for resisting the exploitative and oppressive features of globalization that benefit only the global elite.

According to Barton (2018), Multimodal texts surround us. What are they? How can we use them in our teaching? Effective teaching methods are also needed to teach critical multimodal literacies. These approaches to teaching relate to both the comprehension and composition of multimodal texts. Models of teaching need to be age-appropriate and address students' personal, social and cultural needs. They also need to support students in being able to read texts critically through inferential comprehension. Multimodal literacy describes communication practices that use two or more modes of meaning. Multimodality has become a significant area of research given the broadened range of available designs and media forms in digitally networked and globalized textual ecologies. Language and literacy practices are inherently multimodal because communication requires attending to diverse kinds of meanings, whether of spoken or written words, visual images, gestures, posture, movement, sound, or silence Yet, clearly, the affordances of people-driven digital media and textual production have given rise to an exponential increase in the circulation of multimodal texts in digitally mediated environments. 
Ganapathy (2016), Multimodal Approaches promotes learner engagement in the teaching and learning process of ESL because the students appeared to be positive-minded and motivated to learn with the use of Multimodal Approaches and materials in the class. It affirmed that multimodal approaches made the learners be highly engaged and motivated in doing every task. In a study conducted by Ventayin (2018) on the readiness of DepEd Teachers to online teaching, showed that despite the limited experience in distance education such as technical skills, time management, knowledge and attitude in online education, they were still able to cope with the trends in distance learning. This leads the researcher to investigate the use of multimodal texts in enhancing the student's level of academic performance in afro - Asian literature. It aims to seek if these multimodal texts will be an effective tool to teach the students in times like this that we are facing the new normal.

\subsection{Objectives of the Study}

This study aimed to investigate the effectiveness of multimodal texts in enhancing the academic performance in Afro - Asian Literature in English of Grade 8 students of Pedro Guevara Memorial National High School. Specifically, it sought to answer the following questions:

$>$ What is the level of effectiveness of the teacher-made supplementary materials in terms of usability, suitability and consistency?

$>$ What is the level of effectiveness of multimodal text in the performance of Grade 8 students in Afro-Asian Literature?

$>$ Is there a significant difference between the pre - test and post - test of control group and experimental group?

\section{Methodology}

Describe the research method used in the study. Sampling technique, respondents/participants of the study, setting, research instrument, validation, reliability testing, data analysis (quantitative or qualitative), ethical considerations. Since the objective of the study is to enhance the level of performance of the learners in Afro Asian literature using the developed multimodal texts as a supplementary tool in the teaching and learning process of Pedro Guevara Memorial National High School in Santa Cruz, Laguna, and the researcher utilized the descriptive method of research. Such a method was employed because it involved descriptive, recording, analysis, and interpretations of existing conditions. A descriptive method of research was used in this study wherein the student's responses on the pre and post results were tabulated and computed for their frequencies, averages, mean and standard deviation.

The specific problems were answered by the data gathered through the use of a questionnaire based on multimodal literacy scale and pre-test and post-test as instruments that are anchored in the $\mathrm{K}$ to 12 Curriculum Competencies. The questionnaire was adapted from the study Multimodal Literacy Scale: A Study of Validity and Reliability which was published in Eurasian Journal of Education Research, Issue 61, 2015, 45 - 60. Expert judgment in the fields such as Head Teacher and Master Teachers in the District of Sta. Cruz, Division of Laguna was asked by the researcher to validate the content present in the multimodal texts. This is to ensure that the proposed materials are aligned with the expected competencies for the topics under study.

The test questionnaire was divided into two parts. The first part was the characteristics of multimodal texts in terms of usability, suitability and consistency which was composed of 15 questions. The second part was the components of multimodal texts in terms of objectives, content, development and evaluation which was composed of 20 questions. For the pre-test and post-test, 50 item test questions based from the grade 8 Afro Asian Literature Most Essential Learning Competency (MELC) of the Department of Education was answered by 360 students. Pre-test and post-test served as a tool that measured the student's level of academic performance in Afro-Asian Literature in English through the use of multimodal texts. The instruments were designed in a 
manner wherein respondents of the study provided the writers' answers to the problems that she explores.

In this study, 40 English Teachers in the District of Sta. Cruz, Division of Laguna answered the questionnaires about the effectiveness of the multimodal texts in terms of its characteristics and components and 360 students from grade 8 under Basic Education Curriculum (BEC) and Science and Technology Engineering and Mathematics (STEM) curriculum. The respondents were chosen through the purposive sampling technique.

All respondents from this study were oriented on the procedure and a letter to the parents asking their permission were given as well. Any personal information about the respondents of this study were treated with the utmost confidentiality. The collection of data started when the research instrument was approved by the panel. The questionnaire about multimodal texts was distributed to solicit the views and opinions of experts regarding the supplementary material. The result of validity was consolidated to see the effectiveness of multimodal texts as supplementary materials whether the proposed tool suits the nature, needs and level of the students.

Afterward, upon the approval of the principal of Pedro Guevara Memorial National High School, the researcher asked permission from head teacher to use five selected sections from Basic Education Curriculum and 5 sections from Science and Technology Engineering and Mathematics Curriculum as samples for the study. The chosen respondents undergo pre-test and post-test before and after the implementation of the multimodal texts in classroom instructions. The test result was collected and compared to see if the implementation of multimodal texts in teaching Afro-Asian Literature is effective or not. The results undergone statistical treatment to see if there is significant difference in the pre-test and post-test after the use of multimodal texts as supplementary materials. [Since the study is mainly experimental, the researcher employed statistical testing for hypotheses. This study used the Wilcoxon signed-rank test to find out whether significant difference exists on the scores obtained from pre-test and post-test. Data were presented in tables to show the effectiveness of multimodal texts as supplementary materials.

\section{Results and discussion}

\section{Table 1}

Level of effectiveness on the characteristics of multimodal texts as to usability

\begin{tabular}{lccc}
\hline \multicolumn{1}{c}{ Usability } & Mean & SD & Analysis \\
\hline Serves as instructional materials. & 4.8 & 0.17 & EE \\
Provides discussion and exercises designed to improve learner's technical & 4.8 & 0.17 & EE \\
skills. & & & \\
Serves as a tool for instruction. & 4.7 & 0.41 & EE \\
Offers exercises for reinforcement and mastery of concepts and skills. & 4.6 & 0.25 & EE \\
Serves as an aid to develop high-order thinking skills. & 4.7 & 0.21 & EE \\
& 4.72 & EE
\end{tabular}

Legend: Extremely Effective (EE) - 4.20 to 5.00, Very Effective (VE) - 3.40 to 4.19, Moderately Effective (ME) - 2.58 to 3.39 , Slightly Effective (SE) - 1.80 to 2.59, and Not Effective (NE) - 1.00 to 1.79.

Table 1 presents the evaluation of the Grade 8 English Teachers on the characteristics of Multimodal Texts in terms of usability. The master teachers and teachers rated the Multimodal Text extremely effective in all of its indicator as to serve as instructional Materials $(\mathrm{x}=4.8)$ for the skills to be developed were anchored in the Grade 8 Competencies, provided discussion and exercises designed to improve learners technical skills $(x=4.8)$, served as a tool for instruction $(x=4.7)$, offered exercises for reinforcement and mastery of concepts and skills $(x=4.6)$, served as an aid to develop high order thinking skills $(x=4.7)$. The overall mean of 4.72 indicated that multimodal texts in terms of usability were coherent to the curriculum framework in teaching Afro - Asian Literature for Grade 8 students which covered different learning competencies.

Multimodal texts as supplementary material in terms of usability is self-learning package designed suited for specific learners and teaching objectives. It is self-contained and self-instructional packages with learning paced by each student suitable to his/her needs and ability. It can be used in any setting convenient to the learner and 
Tope, J.

may be completed at learner's own pace. It is structured in such a way that the learners can identify the target objectives for him to achieve at the end of each lesson. It is concerned for each pupil as an individual with his own special aptitude and interest, goal of helping the student to think for himself and allow individuality. Teachers become facilitators rather than traditional dispenser of knowledge. (Khan, 2013).

Table 2

Level of effectiveness on the characteristics of multimodal texts as to suitability

\begin{tabular}{|c|c|c|c|}
\hline Suitability & Mean & SD & Analysis \\
\hline Provides skills that are generally appropriate for secondary learners. & 4.4 & 0.54 & $\mathrm{EE}$ \\
\hline $\begin{array}{l}\text { Includes images, audios appropriate to develop the high-order thinking skills } \\
\text { of the learners. }\end{array}$ & 4.8 & 0.17 & $\mathrm{EE}$ \\
\hline $\begin{array}{l}\text { Provide discussion and exercises suitable to develop the learners' } \\
\text { technological skills. }\end{array}$ & 4.5 & 0.50 & $\mathrm{EE}$ \\
\hline Caters the diversity of learners. & 4.4 & 0.54 & EE \\
\hline Assess objectively the target skill of the learners. & $\begin{array}{l}4.7 \\
4.56\end{array}$ & 0.21 & $\begin{array}{l}\mathrm{EE} \\
\mathrm{EE}\end{array}$ \\
\hline
\end{tabular}

Table 2 shows the evaluation of the Grade 8 English Teachers on the characteristics of Multimodal Texts in terms of suitability. Both master teachers and teachers rated the suitability of the multimodal text as extremely effective in all of its indicators to with provided skills that are generally appropriate for secondary learners $(x=4.40)$, included images, audios appropriate to develop the high order thinking skills of the learners $(x=4.80)$, provided discussion and exercises suitable to develop the learners' technological skills ( $x=4.50)$, catered the diversity of learners $(x=4.40)$ and Assessed objectively the target skill of the learners $(x=4.70)$. The overall mean of 4.56 revealed that the developed Multimodal Text was suitable for the grade 8 students as interpreted as extremely effective. The findings above were supported by Bhat (2014) who stated that instructional materials is one of the valuable devices in the process of learning, that there should be suitable supplementary materials for students so that they learn accordingly with the help of such material.

Table 3

Level of effectiveness on the characteristics of multimodal texts as to consistency

\begin{tabular}{lccc}
\multicolumn{1}{c}{ Consistency } & Mean & SD & Analysis \\
\hline Contains topics that are logically related to each other & 4.4 & 0.54 & EE \\
Provides learning tasks that develop directly the target competencies. & 4.5 & 0.50 & EE \\
Reflects attainable objectives for the lesson & 4.6 & 0.45 & EE \\
Focuses on the main goal which is to develop critical thinking skills. & 4.6 & 0.45 & EE \\
Include exercises that answer the expected outcome of the objective. & 4.6 & 0.45 & EE \\
\end{tabular}

Legend: Extremely Effective (EE) - 4.20 to 5.00, Very Effective (VE) - 3.40 to 4.19, Moderately Effective (ME) - 2.58 to 3.39 , Slightly Effective (SE) -1.80 to 2.59, and Not Effective (NE) - 1.00 to 1.79

Table 3 shows the characteristics of multimodal texts as to consistency. The following indicators were used to rate the consistency of the multimodal text and were interpreted as extremely effective as to it: contained topics that are logically related to each other $(\mathrm{x}=4.40)$, provided learning tasks that develop directly the target competencies ( $x=4.50)$, reflected attainable objectives for the lesson $(x=4.60)$, focused on the main goal which is to develop critical thinking skills $(x=4.60)$ and included exercises that answer the expected outcome of the objective $(\mathrm{x}=4.60)$. The overall mean of 4.54 and interpreted as extremely effective attested that the developed multimodal text characteristics consistency is effective. As mandated by the DepEd Learning Portal (2015) as cited in the study of Aragon (2016), the teachers are encouraged to utilize additional supplementary material to help the students in their needs in particular subject area and developed modules were one of the materials that are beneficial to the teaching learning process in the classroom. The teachers must strictly follow the required list of competencies of $\mathrm{K}$ to 12 Curriculum. The characteristics of an effective supplementary material primarily serves and caters the overall welfare of the pupils as it helps the existing $\mathrm{K}$ to 12 materials in assisting their 
Effectiveness of multimodal texts in enhancing student's level of academic performance

optimum learning possibility. The development of the supplementary materials should be done accordingly to the needs of the learners. The curriculum guide required competencies must be given emphasis in developing this material.

Table 4

Level of effectiveness of the multimodal texts in the performance of Grade 8 students

\begin{tabular}{|c|c|c|c|}
\hline Objectives & Mean & SD & Analysis \\
\hline Clearly stated and easily understood by the learners. & 4.5 & 0.17 & EE \\
\hline Expressed the knowledge and skills to be developed. & 4.4 & 0.17 & $\mathrm{EE}$ \\
\hline Specific and attainable. & 4.5 & 0.41 & $\mathrm{EE}$ \\
\hline Based on the learning competency of Grade 8 Afro - Asian Literature. & 4.8 & 0.25 & $\mathrm{EE}$ \\
\hline \multirow[t]{2}{*}{ Related to the discussion and exercises in the supplementary materials. } & 4.7 & 0.21 & $\mathrm{EE}$ \\
\hline & 4.58 & & $\mathrm{EE}$ \\
\hline
\end{tabular}

Legend: Extremely Effective (EE) - 4.20 to 5.00, Very Effective (VE) - 3.40 to 4.19, Moderately Effective (ME) - 2.58 to 3.39, Slightly Effective (SE) -1.80 to 2.59 , and Not Effective (NE) - 1.00 to 1.79 .

Table 4 presents the level of effectiveness of the Multimodal Text in the performance of Grade 8 students in terms of its Objectives. As reflected both the master teachers and teachers rated the objective of the multimodal text as extremely effective in its entire indicator to with: the objective was clearly stated and can easily understand by the learners $(x=4.50)$, expressed the knowledge and skills to be developed $(x=4.40)$, specific and attainable $(x=4.50)$, based on the learning competency of Grade 8 Afro - Asian Literature $(x=4.80)$, related to the discussion and exercises in the supplementary materials $(\mathrm{x}=4.70)$. The overall mean scores of 4.58 indicated that the multimodal text in terms of Objectives was extremely effective in the performance of grade 8 students. The findings above were supported by Aragon (2016) mentioned in her study that supplementary materials give students specific, clearly focused units of work unlike most textbooks which are often overwhelming. In a module students are presented with one topic at a time so that they can achieve mastery in a particular competency. Furthermore, Pappas (2015) stated that setting clear learning objectives is a requirement on has probably read a thousand time when reading about how to design effective e-learning courses. Providing clear learning objectives for e-learning is also a great tool for building its structure content.

Table 5

Level of effectiveness on the components of multimodal texts as to content

\begin{tabular}{lccc}
\hline \multicolumn{1}{c}{ Content } & Mean & SD & Analysis \\
\hline Appropriate for the learners' level of reading comprehension. & 4.3 & 0.54 & EE \\
Parallel with the objectives and exercises. & 4.7 & 0.17 & EE \\
Contribute to the acquisition of concepts understanding and skills in the & 4.6 & 0.50 & EE \\
required competency. & 4.4 & 0.54 & EE \\
Provides a range of learners' interests and preferences. & 4.5 & 0.21 & EE \\
Sufficient to allow the learners to learn independently. & 4.5 & EE \\
& & &
\end{tabular}

Table 5 presents the mean level of the master Teacher and teachers' evaluation on the developed multimodal texts components in terms of its content. The respondents rated the multimodal text content as extremely effective as to appropriateness for the learners' level of comprehension $(x=4.30)$, parallel with the objectives and exercises. $(x=4.70)$, contributed to the acquisition of concepts understanding and skills in the required competency $(x=4.60)$, provided a range of learners' interests and preferences $(x=4.40)$ and it is sufficient to allow the learners to learn independently $(x=4.50)$. The overall mean score of 4.50 showed that the content of the multimodal text was extremely effective in the performance of grade 8 students as rated by the master teacher and teachers.

As mentioned by Almanza (2018), $\mathrm{K}$ to 12 Toolkit (2012) stated that the $\mathrm{K}$ to12 program is a continuum process for mastery of the learning competencies. In the regular curriculum or the old curriculum, they cram 
Tope, J.

what the students need to learn in 10 years. So the $\mathrm{K}$ to 12 is like decongesting the system so that there are more years for students to master learning skills. Thus there will be more topics to be studied upon by the student in the best learning process they can experience in the school. The skill in selecting the right strategies in the learning content of a lesson is critical. The teacher should be knowledgeable and observant enough on how the students learn to be able to apply the appropriate teaching techniques and strategies. With this it will help the teachers to be equipped in deciding the appropriate method needed.

Excellent instructional material has a big impact on the students learning since students learn most by doing. Together with the excellent instructional materials are its adequate numbers of units in proportion with the number of the students. Engaging in hands on activities gives the learners idea on how this experience can be applied in a real life.

\section{Table 6}

Level of effectiveness on the components of multimodal texts as to development

\begin{tabular}{lccc}
\hline \multicolumn{1}{c}{ Development } & Mean & SD & Analysis \\
\hline Encourage critical thinking, creativity, and problem-solving. & 4.4 & 0.17 & EE \\
Engage and motivate learners. & 4.8 & 0.25 & EE \\
Sufficient to support learning. & 4.6 & 0.50 & EE \\
The direction in the exercises is simple and comprehensive. & 4.5 & 0.41 & EE \\
Realistic, appropriate and can be performed with the resources available to & 4.4 & 0.17 & EE \\
the learner. & & &
\end{tabular}

Legend: Extremely Effective (EE) - 4.20 to 5.00, Very Effective (VE) - 3.40 to 4.19, Moderately Effective (ME) - 2.58 to 3.39, Slightly Effective (SE) - 1.80 to 2.59, and Not Effective (NE) - 1.00 to 1.79.

Table 6 presents the mean level of the Master Teacher and teachers' evaluation on the developed multimodal texts components in terms of its development. Development through activities was conveyed according to the following indicator which is rated by the Master Teacher and teachers as extremely effective as to encourage critical thinking, creativity and problem solving $(x=4.40)$, engaged and motivated learners $(M=4.80)$, sufficient to support learning $(x=4.60)$, the direction in the exercises is simple and comprehensive $(x=4.50)$, realistic, appropriate and can be performed with the resources available to the learner $(x=4.40)$. The following results concluded that the activities of the developed multimodal texts were extremely effective with an overall mean of 4.50 as rated by the master teacher and teachers. Excellent instructional material has a big impact on the students learning since students learn most by doing. Together with the excellent instructional materials are its adequate numbers of units in proportion with the number of the students. Engaging in hands on activities gives the learners idea on how this experience can be applied in a real life Adequacy of Instructional Materials Used by Teachers in Teaching Afro - Asian Literature. (Yamballa, 2018).

Table 7

Level of effectiveness on the components of multimodal texts as to evaluation

\begin{tabular}{|c|c|c|c|}
\hline Evaluation & Mean & SD & Analysis \\
\hline Contains evaluation suited for the learners. & 4.5 & 0.21 & EE \\
\hline Covers the important competencies to be developed. & 4.4 & 0.54 & $\mathrm{EE}$ \\
\hline $\begin{array}{l}\text { Provides pre-assessment focused on specific objectives and content of the } \\
\text { lesson }\end{array}$ & 4.5 & 0.21 & $\mathrm{EE}$ \\
\hline It is written at the level of the learners. & 4.4 & 0.54 & $\mathrm{EE}$ \\
\hline \multirow{2}{*}{$\begin{array}{l}\text { The answer to one item does not furnish or give a clue to the answer in } \\
\text { another item. }\end{array}$} & 4.6 & 0.50 & $\mathrm{EE}$ \\
\hline & 4.5 & & $\mathrm{EE}$ \\
\hline
\end{tabular}

Table 7 shows the findings on the level of effectiveness of multimodal text components in terms of its Evaluation. Assessment is used to evaluate where students are in their learning progress and determine whether 
they are on track to performing well. The developed Multimodal Texts convey affirmative results as extremely effective to all of its indicators as to with contained Evaluation suited for the learners $(x=4.50)$, it covered the important competencies to be developed $(x=4.40)$, provided pre-assessment focused on specific objective and content of the lesson $(x=4.50)$, it is written at the level of the learners $(x=4.40)$ and the answer to one item does not furnish or give a clue to the answer in another item $(\mathrm{x}=4.60)$. It only shows that Master teachers and teachers noticed the value of the assessment to the learners' learning process. Based on the overall mean of 4.50as rated by the Master teacher and teachers the acceptability of the Multimodal Texts' component in terms of Evaluation was extremely effective.

Buasag J. (2013) stated that multimodal texts as instructional materials emphasized on individual learning and its adaptability to large numbers of students promising huge learning opportunity in higher education today. It features evaluation congruent to performance objectives, self-pacing, and frequent feedback. It is a self-contained, independent unit of a planned series of learning activities designed to help the students accomplish certain well defined. The aforementioned features of modular instruction suffice consistency in terms of the learning advantages for the students.

\section{Table 8}

Significant difference of pre-test and post-test of control group

\begin{tabular}{lcccc}
\hline Group & $\begin{array}{c}\text { Computed } \\
\text { Value }\end{array}$ & $p$-Value & Decision & Interpretation \\
\hline $\begin{array}{l}\text { Control } \\
\text { Group }\end{array}$ & -2.023 & 0.0431 & $\begin{array}{c}\text { Reject the } \\
\text { Null Hypothesis }\end{array}$ & $\begin{array}{c}\text { There is significant difference between the } \\
\text { pre-assessment scores and the post-assessment } \\
\text { scores. }\end{array}$ \\
\hline $\begin{array}{l}\text { Legend: } \text { Extremely Effective (EE) }-4.20 \text { to } 5.00, \text { Very Effective (VE) }-3.40 \text { to } 4.19, \text { Moderately Effective (ME) }-2.58 \text { to } 3.39, \text { Slightly } \\
\text { Effective (SE) }-1.80 \text { to } 2.59 \text {, and Not Effective (NE) }-1.00 \text { to } 1.79 .\end{array}$
\end{tabular}

The Wilcoxon signed-rank test was used on the control group, which includes the sections G. Zara, F. Del Mundo, J. Rizal, Diamond, and Ruby. With the $p$-value of 0.0431 , the null hypothesis of no significant difference is rejected at $5 \%$ level of significance. Thus, there is a significant difference between the pre-assessment scores and the post-assessment scores of the Grade 8 students from the aforementioned sections. The findings shown above supported the study of Sanchez (2016) stated that modification in the performance of the students is noted through the result of the posttest. There is always a tendency that the performance improved in the posttest by any means of teaching and learning process. When learners take pretest they had limited knowledge on the topics whereas when learners take posttest they upgraded their knowledge on the topics that were discussed.

\section{Table 9}

Significant difference of pre-test and post-test of experimental group

\begin{tabular}{ccccc}
\hline Group & $\begin{array}{c}\text { Computed } \\
\text { Value }\end{array}$ & $p$-Value & Decision & Interpretation \\
\hline $\begin{array}{c}\text { Experimental } \\
\text { Group }\end{array}$ & -3.381 & 0.007 & $\begin{array}{c}\text { Reject the Null } \\
\text { Hypothesis }\end{array}$ & $\begin{array}{c}\text { There is significant difference between the } \\
\text { pre-assessment scores and the post-assessment } \\
\text { scores. }\end{array}$ \\
\hline
\end{tabular}

The experimental group consists of the remaining sections not mentioned in the control group. The results show that at 0.05 level of significance, there is a significant difference between the pre-assessment and the post-assessment scores of the remaining sections of the Grade 8 students. Despite of the unique multi intelligence of the students, it is unavoidable that their weakness to possess certain skills can affect their overall performance in particular subject. Logically, as the achievement gap grows larger, the odds of students closing it become increasingly less likely. Schools must take action early, in order to target students' needs in developing their skills. For school sites where funding is limited, it is possible that the limited resources available for early intervention programs can be allocated thus intervention such as multimodal texts or other modular instruction can help address the learning gap especially in terms of assessing the capabilities of the students (Gecalao, 
Tope, J.

2017).

\section{Conclusion and recommendation}

Based from the findings of the study presented, the following conclusions were hereby drawn:

$>\quad$ The multimodal text is extremely effective as to its characteristics in terms of: usability, suitability and consistency. It is evidently usable, suitable, consistent and well laid out as validated by the master teacher and teachers in Pedro Guevara Memorial National High School.

$>$ The multimodal text is extremely effective as to its components in terms of: objectives, contents, development and evaluation through the master teachers and teachers I - III. The multimodal text is uniquely designed with varied activities that are based on its curriculum which definitely makes the student's learning more engaging, interactive, collaborative and interesting.

$>\quad$ There is a significant difference between the pre assessments and post assessments of control group and experimental group. Thus, the null hypothesis was rejected.

$>\quad$ The developed multimodal texts had a positive effect on the students learning of Afro - Asian Literature. They can result in greater depth of understanding by presenting multiple input modalities and increasing motivation among learners.

Considering the findings and conclusions in the study, the following recommendation is advised:

$>\quad$ The Department of Education may provide trainings for teachers on how to develop supplementary materials like multimodal texts which are usable, suitable and consistent.

$>$ Teachers may develop multimodal texts anchored to Grade 8 Competencies. The contents and objectives must be aligned with the content standard of the curriculum. The development and assessment must be jived with the performance standard of the curriculum.

$>\quad$ Teachers should attend seminars and update themselves with different teaching strategies suited for the 21 st century learners.

$>\quad$ The learners need to be assisted in terms of providing more validated supplementary materials in enhancing their high order thinking skills for them to remain motivated and interested in learning.

$>\quad$ The material may be utilized by students with difficulties for remedial teaching or as additional task for fast learners in Science and Technology Engineering Mathematics classes.

$>\quad$ School Heads may strengthen their faculty and staff development programs such as seminars and workshops on developing supplementary materials which can be adopted in the teaching and learning process.

\section{References}

Aberg, J. (2017). Design and recognition of multimodal texts: selection of digital tools and modes based on social and material premises? https://doi.org/10.1007/s40692-017-0088-3

Almanza, B. (2018). Development of reading skills and modular approach in phoneme segmentation among kindergarten pupils (Unpublished Master's Thesis). Laguna Polytechnic State University, San Pablo Campus, San Pablo City.

Aragon, C. (2017). Supplementary material in enhancing reading comprehension of Grade 7 students

(Unpublished Masters Thesis). Laguna Polytechnic State University, LosBaños, Los Baños Laguna.

Barrot, M. (2018). English curriculum reform in the Philippines: Issues and challenges from a 21st century 
learning perspective. https://doi.org/10.1080/15348458.2018.1528547

Barton, S. (2018). Multimodal texts surround us. What are they? How can we use them in our teaching?

Retrieved from https://www.aare.edu.au/blog/?p=3545

Buasag, J. V. (2013). Multimodal texts as instructional materials.

Capulso, N. (2020). Braving the K-12 education in the Philippines amidst the COVID-19 pandemic. https://doi.org/10.4300/JGME-D-20-00276.1

DepEd Order No 011, s 2020. Revised guidelines on alternative work arrangements in the Department of Education during the period of state of national emergency due to COVID-19 pandemic. Retrieved from

https://www.deped.gov.ph/wpcontent/uploads/2020/06/DO_s2020_011-Revised-Guidelines-on-Alternat ive-Work-Arrangements.pdf

Ganapathy, M. (2016). The effects of using multimodal approaches in meaning-making of 21 st century literacy texts among ESL students in a private school in Malaysia. Retrieved from https://www.researchgate.net/publication/291832662_The_Effects_of_Using_Multimodal_Approaches_ in_Meaning

Grade 8 English Most Essential Learning Competencies. Retrieved from http://guroako.com/2020/06/02/most-essential-learning-competencies-melcs-complete-files/

K to 12 Curriculum Guide in English Grade 1-10. DepEd Complex, MERALCO Avenue Pasig City. (2013). https://www.deped.gov.ph/wp-content/uploads/2019/01/Arts-CG.pdf

Khan, M. (2013). Effectiveness of modular teaching in biology at secondary level. Asia Social Science, 6(9).

Malik, T. (2019). Comparative analysis between pre- test/post-test model and post-test-only model in achieving the learning outcomes. Ophthalmol, 35(1). https://doi.org/10.36351/pjo.v35i1.855

Pappas, C. (2015). Writing learning objectives for e-learning. Retrieved from https://elearningindustry.com/writing-learning-objectives-for-elearning-what-learning-professionals-sho uld-know

Yamballa, J. (2018). Development of supplementary module in reading (Unpublished Masters Thesis). Laguna Polytechnic State University, Sta. Cruz, Sta. Cruz, Laguna. 
Tope, J.

110 Consortia Academia Publishing (A partner of Network of Professional Researchers and Educators) 